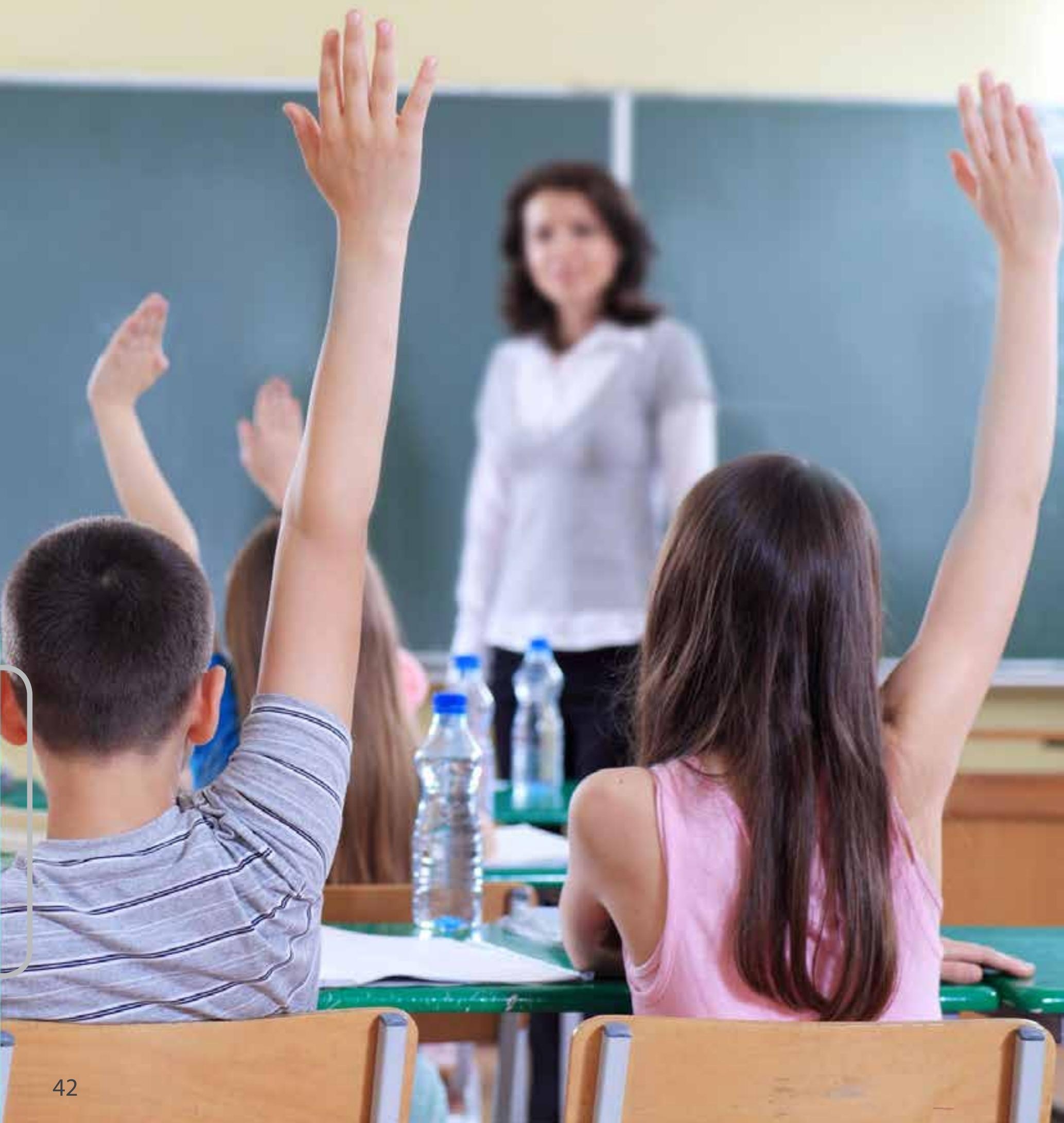




\section{ESTUDIOS DE CASO EN LA ENSEÑANZA DE LA BIOLOGÍAY LA EDUCACIÓN PARA LA SALUD EN ESCUELA MEDIA*}

\section{Case studies in Biology teaching and health education in Secundary School}

Andrea Revel Chion'

Fecha de recepción: 18 de febrero de 2013 Fecha de aprobación: 19 de mayo de 2013

\section{RESUMEN}

Se presentan los estudios de caso como herramienta didáctica para la enseñanza de la biología y la educación para la salud en la educación secundaria (estudiantes de entre 16 y 17 años). Se diseñaron, pusieron en marcha y evaluaron algunas actividades orientadas al logro de procedimientos cognitivos de orden superior y también de estrategias centrales de la investigación científica como la identificación de problemas y la formulación de hipótesis. Las actividades se presentan y estudian como casos con formato narrativo. Se han utilizado casos con temáticas motivadoras que, a su tiempo, ofrecen un panorama amplio del contexto en el que se realizaron algunos descubrimientos o invenciones científicas, su aplicación, las consecuencias sociales que esto produjo, y ciertas pinceladas acerca del carácter, la personalidad o las actitudes de los actores involucrados.

Palabras clave: casos, narrativas, enseñanza de la biología, educación para la salud.

\section{ABSTRACT}

Case studies are presented as didactic tools for Biology teaching and Health Education at secondary school (students between 16 and 17 years old). Some activities orientated to the teaching of higher-order cognitive procedures were designed, carried out and evaluated, as well as main strategies for scientific research such as the identification of problems and the statement of hypotheses. The activities are characterized for being presented and studied as cases with a narrative format. Cases with motivating topics have been used which, in turn, offer a broad outlook of the context in which some discoveries or scientific inventions were made, what their application was like and the social consequences they produced. A few comments about the character, personality and attitudes of the actors involved are also included.

Keywords: Cases, Narratives, Biology Teaching, Health Education.

* El trabajo se deriva de la investigación en torno a los estudios de caso y su aplicación a la enseñanza en escuela secundaria.

1 Docente e investigadora del Instituto CeFIEC. Facultad de Ciencias Exactas y Naturales. Universidad de Buenos Aires. Doctora en Ciencias Naturales con mención en Didàctica de las Ciencias Experimentales. Correo electrónico: andrearevelchion@yahoo.com.ar 


\section{INTRODUCCIÓN}

Selma Wasserman (1994, p. 19) afirma: "una característica obvia del método de casos es el empleo de una herramienta educativa llamada caso". Los casos pueden ser considerados porciones de la realidad que se vehiculizan en formato narrativo y se estructuran en relación con grandes ideas o problemas relevantes; dan cuenta también de situaciones complejas $y$, por tanto, no tienen una resolución unidireccional. De acuerdo con esta autora, por su propia naturaleza los casos son interdisciplinarios ya que, aunque se centran en un tópico científico determinado, incluyen para su presentación aspectos sociales, históricos, biográficos, psicológicos, éticos, geográficos, etc.

Los estudios de caso recuperan el formato narrativo cuya estructura ha sido el vehículo por excelencia para compartir información y cambiar creencias a lo largo de la historia de la humanidad, por esta razón se suele afirmar que el rasgo más distintivo del ser humano como especie es su capacidad de contar historias (Igartua, 2011). En esa misma línea, el novelista y lingüista David Lodge (2002) afirma que la narrativa es una de las operaciones fundamentales de construcción de sentido que posee la mente $y$, aparentemente, es peculiar tanto de los individuos como de la humanidad en su conjunto. Será precisamente esta peculiaridad universal lo que constituye a las narrativas en un potente recurso para la enseñanza. Los relatos han sido enormemente importantes en las culturas con tradiciones orales para transmitir historias acerca de cómo se desarrollaron los conocimientos y se crearon nuevas ideas. Como la moderna cultura alfabeta conserva aún prácticas orales importantes, las narrativas siguen desempeñando un papel vital y fundacional en la enseñanza y el aprendizaje (Mc Ewan y Egan, 2005), por tanto los casos, cuyo formato es precisamente el que caracteriza a los relatos, se constituyen en una vía sumamente potente para la presentación de ciertos contenidos escolares. El problema central de un caso está representado, en la situación didáctica, por el contenido relevante o central del currículum escolar prescripto que se pretende abordar.

\section{Los casos y la aplicación didáctica}

Los casos sugieren o exponen problemas y abren interrogantes que favorecen su análisis. Para el abordaje de los contenidos que encaran los casos se requiere que los estudiantes pongan en juego diversas destrezas, por ejemplo, la formulación de preguntas adecuadas que favorezcan su tratamiento. Precisamente, es la calidad de las estrategias requeridas, lo que los puede convertir en una herramienta potente para el aprendizaje de las ciencias naturales. La enseñanza de la biología a partir de estudios de casos favorece que los estudiantes se formen una idea de conjunto sobre una determinada cuestión, diferencien opiniones de hechos, y comuniquen sus puntos de vista sustentándolos en datos relevantes y pertinentes. En relación con este último aspecto, aferrarse al modelo teórico de referencia es fundamental, ya que esto podría limitar o inhibir el margen para que los estudiantes aporten ideas del sentido común a la resolución del caso. Como plantea Claxton (2001), los ciudadanos necesitan ser capaces de poder hablar y comprender el lenguaje

1 El resaltado es mío. de las ciencias para participar, aunque no sea activamente sino solo mentalmente, de los debates sobre temas científicos que los involucre; al mismo tiempo conocer este lenguaje es necesario para identificar las diferencias entre ciencias y pseudociencias y evitar así que las personas por no saber se retiren a posiciones de fe ciega o den crédito a publicaciones de sospechosa autoridad.

El estudio de un caso es el punto de partida para que los estudiantes indaguen sobre problemas genuinos o auténticos (Wasserman, 1994). Un caso, trabajado en grupos colaborativos, puede proporcionar a los estudiantes sus primeras experiencias de investigación guiada en el marco de la investigación científica. La autora plantea:

\begin{abstract}
Una vez diseñado el caso, hay numerosas posibilidades en lo que se refiere a las actividades de seguimiento que elige el docente para profundizar y enriquecer la comprensión de los alumnos. La elección de las actividades, la medida en que estas se emplearán y el tiempo que se les dedicará son cuestiones que cada docente resuelve según las circunstancias. Lo importante cuando se eligen estas nuevas experiencias es que la investigación de los alumnos siga desarrollándose a través del examen inteligente de los problemas importantes (p. 27).
\end{abstract}

\section{Una tipología de los casos}

Una forma posible de categorizar los casos es en explicativos y paradigmáticos, asumiendo que es posible -o incluso deseable- diseñar o encontrar ejemplos mixtos. Los casos de tipo explicativo se exponen en forma paralela a la temática que se está explicando, con el objetivo de que los estudiantes logren articular de un modo fructífero la teoría y la práctica, ya que actúan como ejemplos o modelos del contenido que se está estudiando. Cuando se presentan, por ejemplo, contenidos relacionados con la síntesis de proteínas, que muy extendidamente suponen dificultades para su comprensión, se pueden exponer casos que iluminen la relación entre genes y fenotipo. El caso de la investigación del gen del habla (FOXP2) -que regula algunos movimientos del rostro y la mandíbula, presente en monos y humanos, cuyas mutaciones habría permitido el desarrollo del lenguaje articuladopodría amortiguar la dificultad de comprensión a partir de un proceso de modelaje a partir del análisis de un fenotipo tan particular como la adquisición del lenguaje.

Los casos paradigmáticos, por su parte, contienen conceptos centrales, ejemplificadores y estructurantes de la disciplina, constituyendo lo que Schwab (1978) denomina la estructura sintáctica de la disciplina. En la enseñanza de la biología, por ejemplo, podría reconocerse como caso paradigmático las dificultades enfrentadas por Ignaz Semmelweis para persuadir a los médicos de la sala a cargo del profesor Klin, en el Hospital General de Viena, de la dramática relación entre el lavado de manos y el enorme número de casos de muertes debidas a la fiebre puerperal (Céline, 2009). Asimismo, el caso de Luis Pasteur, y sus vehementes intentos por persuadir a la comunidad científica acerca del equívoco en la creencia en la generación espontánea (Dubos, 1953) se constituye en otro caso fundamental. A modo de ejemplo se transcribe la declaración que el 7 de abril de 1864 realizó Pasteur en la Sorbona y que, en función de su contundencia, debería formar parte del caso. 


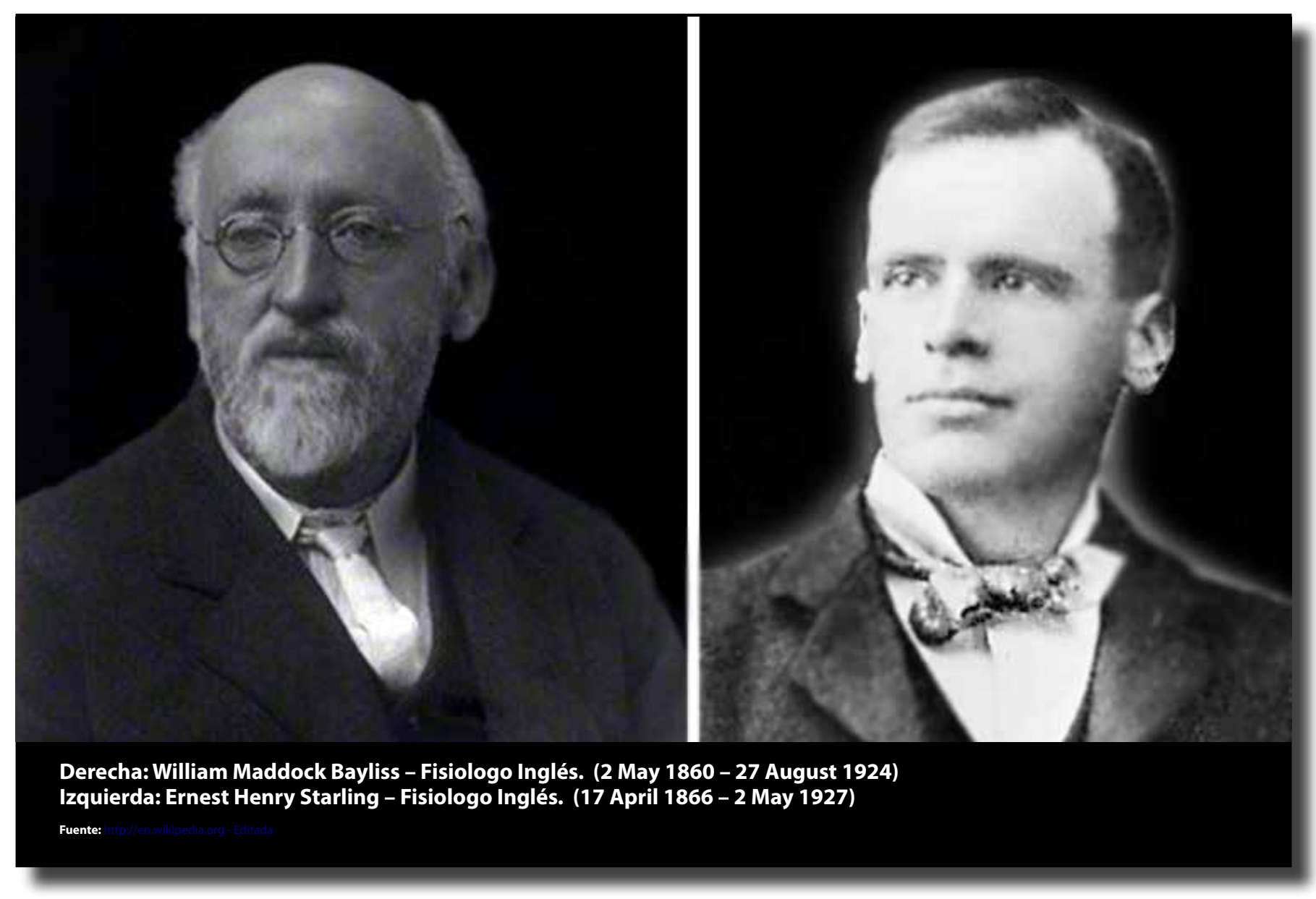

Y por lo tanto, caballeros, puedo apuntar a ese líquido y decirles: he tomado mi gota de agua de la inmensidad de la Creación, y la he tomado repleta de los elementos apropiados para el crecimiento de los seres inferiores. $Y$ espero, vigilo, escudriño; la ruego que comience para mí de nuevo el hermoso espectáculo de la primera creación. Pero está muda, muda desde que hace varios años comencé estos experimentos; está muda porque la he guardado de la única cosa que no sabe el hombre cómo producir: de los gérmenes que flotan en el aire, de la vida, porque la vida es un germen y un germen es la vida. Jamás se recuperará la doctrina de la generación espontánea del golpe mortal de este simple experimento (Dubos, 1953, p. 153).

En lo que atañe a la asignatura Educación para la Salud -de carácter obligatorio en el currículum oficial de la República Argentina- podrían identificarse como casos paradigmáticos el de las enfermedades transmitidas por vectores ubicados en zonas de pobreza extrema, por ejemplo la enfermedad de Chagas-Mazza, o el caso del control de la epidemia de cólera en Londres en 1854, por John Snow que, adhiriendo a la teoría contagionista, se enfrentó a la teoría miasmática para alegar que el control del agua, que contenía una materia mórbida, era la intervención adecuada para frenar las epidemias recurrentes -entre muchos otros casos-.

\section{Propuestas didácticas}

Se presenta una serie de actividades didácticas diseñadas para estudiantes de escuela secundaria avanzada (16 a 17 años) orientadas a la enseñanza de algunos procedimientos cognitivos y comunicativos relacionados con la investigación científica, como:
- La identificación de problemas.

- La formulación de hipótesis.

- La contrastación de las mismas.

- La producción de explicaciones.

Los casos se estructuran en relatos motivadores que ofrecen un panorama del contexto general en el que se produjeron ciertas ideas científicas innovadoras, y pinceladas acerca de la personalidad y las actitudes de los científicos involucrados en tales procesos de innovación.

\section{Caso 1. La producción hormonal del páncreas}

En los inicios del siglo XX, los fisiólogos ingleses William Maddock Bayliss y Ernest Henry Starling se encontraban abocados al estudio de la función endocrina del páncreas. El problema que les interesaba giraba en torno a los modos como el páncreas recibía la orden de liberar sus secreciones al intestino delgado. Para entonces, solo era conocida la coordinación realizada por medio del sistema nervioso y, ubicados en esa concepción de la regulación de las funciones corporales, los investigadores diseñaron un experimento para poner a prueba la hipótesis según la cual la orden en cuestión era dada por ese sistema. Así, tomaron la decisión de cortar los nervios que inervaban el páncreas de un perro y, para su sorpresa, el páncreas siguió liberando sus jugos normalmente. 
Más tarde atribuyeron este proceso a una sustancia, a la que llamaron hormona secretina. Esta propuesta indujo a otros investigadores a sospechar que el páncreas podía ser responsable de la producción de otra hormona, relacionada con la diabetes. Para entonces, algunos experimentos habían dejado de manifiesto que si el conducto pancreático era bloqueado, la mayor parte del páncreas se resecaba, a excepción de un grupo de células, los islotes de Langerhans - llamados así en honor al investigador Paul Langerhans que los había estudiado sin lograr identificar su función-. En 1916, el médico escocés Edward Albert Sharpey-Schafer recordó el trabajo en el que se mencionaba a aquellos islotes y sugirió que podían ser los responsables de la producción de la hormona bautizada por él mismo como insulina, un nombre cuya raíz latina proviene de la palabra insula, que significa isla.

Luego de reiterados intentos fallidos de extraer insulina del páncreas de animales para tratar la diabetes humana, dos investigadores canadienses, retomando viejos experimentos, encontraron una técnica de obtención viable. El novelista y científico Isaac Asimov (1973, p. 670) relata de esta forma aquel logro:

En 1921 el médico canadiense Federick Grant Banting y el fisiólogo Charles Herbert Best (que trabajaban en los laboratorios de John MacLeod en la Universidad de Toronto) intentaron dar un nuevo enfoque al asunto. [...] Primeramente bloquearon el conducto pancreático. La porción de la glándula que producía la enzima se resecó [...] y los científicos pudieron extraer la hormona intacta a partir de los islotes. [...] En 1923, Banting y, por algún motivo, Mac Leod (cuyo único servicio al descubrimiento de la insulina fue permitir la utilización de su laboratorio durante el verano, mientras estaba de vacaciones) recibieron el premio Nobel de fisiología y medicina.

La propuesta de trabajo a partir de este caso es la siguiente:

1. Se presenta el caso a los estudiantes en forma oral y se les provee una versión escrita, de manera tal que puedan consultarla para las actividades que se les propondrá posteriormente.

2. Se pide a un estudiante que re relate el caso

3. Los estudiantes de la clase pueden hacer aportes o correcciones.

4. Otro estudiante realiza una interpretación explicativa del caso.

5. Se propone al resto de la clase que expliciten los acuerdos y desacuerdos sobre los conceptos y procedimientos analizados y discutidos. El objetivo de esta instancia es que este discurso compartido sea útil para debatir sobre las diferencias de significado y de interpretación, es decir, para aproximar los saberes que se pretende que los estudiantes alcancen y las concepciones puestas en movimiento. Esta negociación de significados es una instancia fundamental de la secuencia ya que promueve que se establezcan los alcances que se les otorgará, en el marco del trabajo, a los conceptos.
El significado no es preexistente sino que es construido conjuntamente por los interlocutores en el acto mismo de la comunicación. Los interlocutores cooperan en su construcción, que no puede adjudicarse al emisor o al receptor sino que pertenece conjuntamente a ambos, porque surge en el proceso de interacción. Solo existe en el espacio de intersubjetividad o subjetividad compartida. Se dice que el significado se negocia para destacar el papel que cumplen todos los interlocutores en su creación. (Alemany, 1998, p. 26).

\section{En relación con el caso, los estudiantes deberán:}

Identificar los conocimientos disponibles al momento de realizarse los experimentos relatados.

- Analizar las consecuencias del bloqueo del conducto pancreático a la luz de lo que se sabía en esa época: ¿qué sucedería con el páncreas luego de esta maniobra? ¿Qué funciones se verían alteradas en el perro y cuáles permanecerían intactas? (Se busca que los estudiantes recuperen sus conocimientos respecto de las funciones enzimáticas del jugo pancreático).

- Formular algunas preguntas que se podrían haber planteado los investigadores antes de realizar el experimento (identificación del problema científico).

- Sugerir posibles hipótesis que los científicos podrían haber formulado ante los resultados del mismo.

- Analizar y discutir los aportes resultantes del experimento.

- Elaborar un texto explicativo que incluya: resumen del relato, problema planteado por los investigadores, hipótesis propuestas y aportes concretos a la comprensión de la fisiología del páncreas desde el punto de vista hormonal.

\section{Caso 2. El hantavirus americano}

La problemática de la salud es particularmente adecuada para ser tratada con esta estrategia didáctica en virtud de la multiplicidad de elementos que se conjugan, por ejemplo, en la emergencia y reemergencia de las enfermedades. Efectivamente interpretaciones más complejas, superadoras del clásico modelo biologicista (Maglio 2008), consideran que las causas que se alinean para la emergencia de una enfermedad no se agotan en las biológicas sino que, por el contrario, es necesario advertir que existen elementos del ámbito social que condicionan y potencian la expansión de las noxas biológicas, como se advierte en las epidemias, endemias y pandemias en diferentes momentos históricos.

El siguiente caso está basado en un extenso tratamiento que se realiza de un brote de hantavirus americano en el libro Ahí viene la plaga (Lozano, 2004).

El Bolsón, valle cordillerano situado al sur de la provincia de Río Negro, es uno de los destinos turísticos preferidos de la Patagonia argentina. En 1996, esta comarca fue el es- 
cenario de una situación dramática: un grupo de personas contrajo una enfermedad -caracterizada por alta fiebre y problemas respiratorios- que resultó ser mortal para la mayoría de los afectados. Especialistas del Instituto Malbrán² de Buenos Aires, realizaron análisis que determinaron que la enfermedad se debía a una infección causada por el hantavirus llamado Andes. Los hantavirus son un grupo de virus que producen enfermedades hemorrágicas con una alta tasa de mortalidad. El virus Andes, en particular, produce una enfermedad con síntomas pulmonares severos.

Por otro lado, investigadores del Instituto Nacional de Enfermedades Virales Humanas "Dr. Julio Maiztegui", de la ciudad de Pergamino, en la provincia de Buenos Aires, habían mostrado que un roedor frecuente en El Bolsón, el ratón colilargo, era el reservorio natural del virus. A partir de esos datos, se estableció la idea de que el contagio se producía cuando las personas entraban en contacto con las secreciones de los roedores, desestimándose la posibilidad de que existiera el contagio interhumano.

En el marco del estudio de algunos problemas sanitarios argentinos y de la discusión acerca de los alcances del concepto de enfermedad emergente, se presenta a los estudiantes el caso real de una paciente.

En octubre de 1996, Agustina, la hija de un ex juez de Buenos Aires, viajó a la ciudad de Ingeniero Jacobacci, en la provincia de Río Negro, a varios centenares de kilómetros de la localidad de El Bolsón. El motivo de su viaje no era pasar sus vacaciones sino asistir al entierro de su abuela que, al igual que un tío, había muerto debido a una infección causada por el virus Andes. Los padres de Agustina habían llegado a El Bolsón en su camioneta un tiempo antes para acompañar a la anciana en sus últimos días. Allí guardaron la camioneta en un galpón, en el que, entre otras cosas, la anciana había almacenado nueces. Luego del fallecimiento de la abuela de Agustina, el juez y su esposa, se dirigieron a Ingeniero Jacobacci acompañados por Flora, la empleada doméstica de la abuela.

Al poco tiempo, Flora comenzó a mostrar los síntomas típicos de la enfermedad. El juez, desconfiando de los servicios de salud del lugar, decidió que todos volverían en su camioneta a Buenos Aires, donde Flora sería tratada en un centro médico de alta complejidad. Durante el viaje, por momentos Flora sentía frío y por momentos calor (debido a los intermitentes episodios de fiebre producidos por la enfermedad), por lo que el juez prendía la calefacción y el aire acondicionado alternativamente. Flora murió poco tiempo después de llegar a Buenos Aires. Luego fueron internados el juez y su esposa y, finalmente, Agustina. Tanto Flora, como el juez y su esposa habían pasado por El Bolsón, sin embargo, Agustina no había estado en allí.

Los médicos de Buenos Aires, sin dudar de su concepción según la cual la única vía de contagio era a través del contacto con las secreciones de los roedores, e ignorando, por tanto, la posibilidad de transmisión interpersonal, aseguraron

2 Instituto de investigación microbiológica dependiente del Ministerio de Salud de la República Argentina. que el contagio de Agustina se había producido al utilizar la camioneta que había permanecido durante un tiempo en El Bolsón. Allí, mientras la camioneta estaba guardada en el galpón, los ratones colilargos habrían ingresado al vehículo por los conductos de ventilación, donde habrían dejados sus secreciones. Así, Agustina y sus padres se habrían infectado al encender la ventilación de la camioneta, contaminada por los roedores. Otra posibilidad era que el virus estuviera en un abrigo de la empleada de la abuela, que Agustina había utilizado durante el viaje.

Posteriormente, sin embargo, se constató que algunos médicos de Buenos Aires habían contraído la enfermedad después de atender a una médica -nunca había estado en El Bolsón- y que había asistido a los primeros pacientes de la enfermedad, lo que sugirió la posibilidad de que el contagio tuviera lugar también de persona a persona.

El aumento de casos en El Bolsón generó una suerte de histeria colectiva que resultó en una disminución de la actividad turística en el lugar, en donde esta se constituye en la principal fuente de ingresos. Ante esta situación, funcionarios locales acusaron a médicos e investigadores de participar de una campaña para desprestigiar la región. Ante la aparición de casos de la enfermedad en Chile, una periodista chilena sugirió que la culpa era de los argentinos.

Este caso aborda contenidos centrales de la asignatura Educación para la Salud. El enfoque que se adopta para el desarrollo de las cuestiones científicas coloca a la salud en una clara y estrecha relación con el ambiente, considerado este en sentido amplio. Así, el estudio de este caso persigue alertar precisamente respecto de las condiciones ambientales que propiciaron el brote de la enfermedad y qué aspectos del contexto político y social del ambiente orientaron los modos en los que se enfrentó el brote.

Para el trabajo sobre este caso, las instancias 1 a 5 se repiten como en la propuesta anterior. El punto 6 propone:

- Análisis de las actitudes de los actores involucrados que se consideren más relevantes para comprender el caso.

- Estimación del impacto de las decisiones tomadas por ellos.

- Identificación de las condiciones ambientales que propiciaron la expansión de la enfermedad (en este punto se espera que los estudiantes puedan establecer similitudes con el caso de la peste negra medieval, analizado con anterioridad en la asignatura, como estrategia de resolución transferencial).

- Análisis de la pertinencia de haber catalogado el caso en cuestión como brote epidémico, con las consecuencias sociales que ello trajo para la comunidad.

- Reconocimiento de la significación del hecho de que la comunidad científica se aferrara al dogma dominante para la interpretación de los modos de contagio de la enfermedad. 


\section{Caso 3. La beba de los hilitos azules}

El siguiente caso forma parte de un exhaustivo análisis de historias personales resueltas a través de pruebas de ADN presentadas en el libro La identidad (Bernath, 2007). Uno de los capítulos se aboca a describir casos en los que recobraron su identidad niños apropiados durante la dictadura militar en la Argentina.

La dictadura militar en la Argentina (1976-1983) dejó un saldo trágico de 30.000 personas desaparecidas y aproximadamente 500 niños apropiados, la mayoría de ellos, luego de que sus madres dieran a luz en cautiverio. La asociación Abuelas de Plaza de Mayo que se creó a comienzos del proceso militar, aún continúa buscando a los nietos faltantes.

Victoria Donda Pérez nació en la Escuela de Mecánica de la Armada (ESMA) en 1977 y fue separada de su madre 15 días después, antes de lo cual su mamá prendió dos hilos azules a las orejas de la bebé, con la esperanza de que sirvieran para su identificación.

Cuando Victoria cumplió 24 años, un grupo de colaboradores de Abuelas de Plaza de Mayo le comunicó que existía la sospecha de que fuera hija de desaparecidos. Algunas investigaciones que habían realizado -y que continuó Victoria por su cuenta- abonaban dicha sospecha: el certificado de nacimiento indicaba que el parto había sido en un domicilio particular y lo firmaba un médico procesado por apropiación de menores. Nadie recordaba haber visto embarazada a su madre de crianza; su padre de crianza era un militar vinculado a la dictadura y una mujer que había estado detenida junto a su madre biológica y que la asistió en el parto relató el episodio de los hilitos azules. Victoria pudo averiguar que se realizó una denuncia ante la fundación Abuelas de Plaza de Mayo en la que se afirmaba que le habían llevado a una bebé con unos hilitos azules en sus orejas, que se negaba a tomar mamadera para que ella, que acababa de dar a luz, la amamantara.

Ante todas estas evidencias Victoria - Analía hasta ese momento- accedió a realizarse el examen de ADN que indicó que había un 99,99 \% de posibilidades de que perteneciera a la familia Pérez Donda. Tiempo después averiguó que el hermano de su padre que trabajaba en la ESMA era el responsable de la muerte de sus padres. En la actualidad, Victoria Donda Pérez tiene una activa militancia política y es diputada nacional, sus padres de crianza cumplen condena por su apropiación.

Para el trabajo sobre este caso, las instancias 1 a 5 se repiten como en la propuesta anterior. El punto 6 propone:

- Análisis y discusión de las derivaciones de la recuperación de la identidad.

- Según Bernath (2007), existen diferentes instancias que conforman la identidad; la identidad formal que supone el otorgamiento de un documento que acredita quién se es; la identidad psicológica que permite reconocerse a uno mismo y a través de la cual familiares y amigos nos reconocen; una identidad social determinada por la nacionalidad, la lengua, el sitio donde se vive y las actividades que cada uno realiza, y una identidad biológica que por medio de los estudios de ADN hace posible la identificación de un individuo que es, además, único y biológicamente excepcional. A partir del caso planteado se propone a los estudiantes reconocer los matices que cada una de las identidades caracterizadas podrían tener.

- Analizar qué significa que la prueba de ADN de Victoria diera un resultado del 99,99\%.

- Investigar y realizar una descripción de cómo se realizan los exámenes para determinar identidades.

- Cuando Victoria viajó a Canadá a conocer a parte de su familia materna se produjo un hecho que dejó a todos sorprendidos. Luego de un almuerzo, mientras algunos retiraban los platos donde habían comido pasta, otros traían chocolates para el postre. Victoria inmediatamente tomó un trozo de chocolate y lo untó con el queso de la pasta. Sus familiares, perplejos, primero, y emocionados después, le contaron que sus padres biológicos tenían algunos gustos muy particulares como comer chocolate con queso o chorizo con dulce.

- Analizar qué inferencias pueden hacerse acerca de la herencia de este tipo de particularidades.

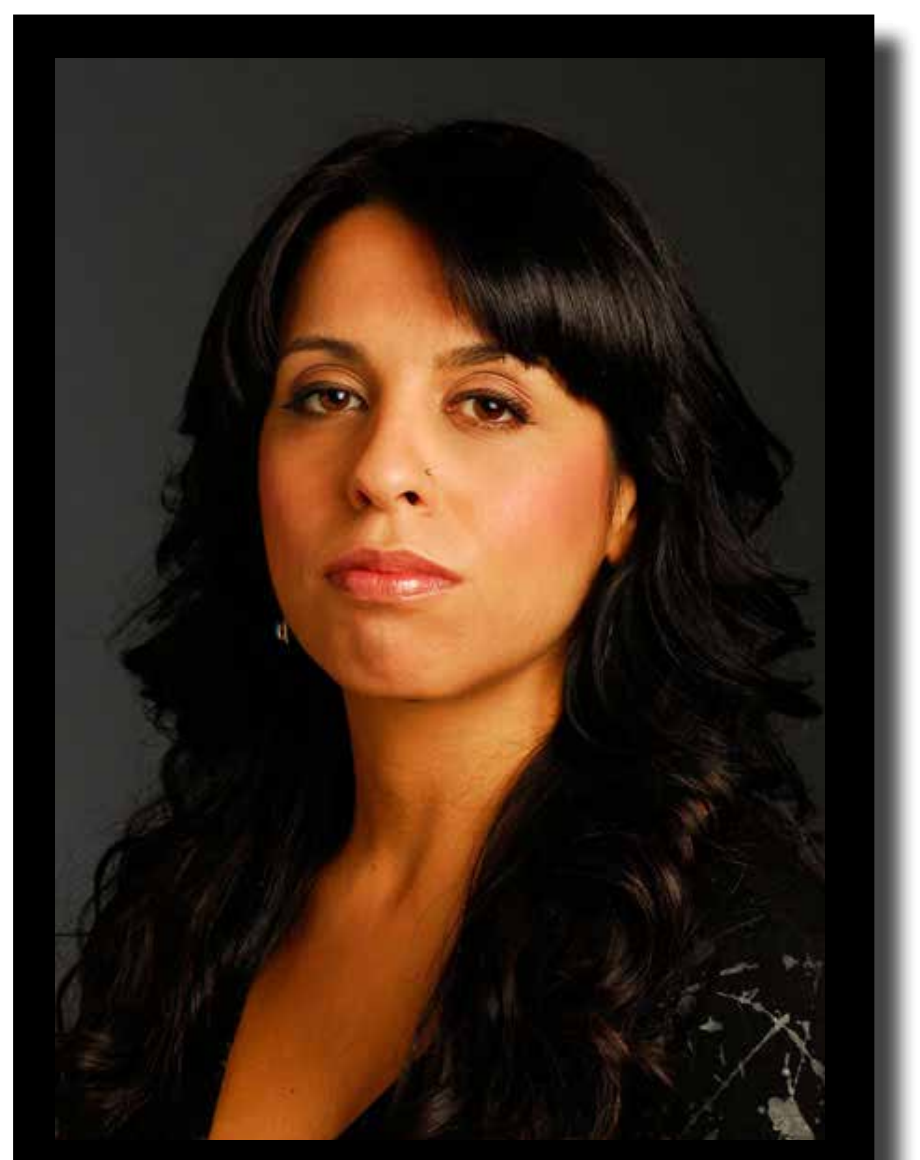

Victoria Donda fue separada de su madre 15 días después de su nacimiento. La dictadura militar Argentina dejo aproximadamente 500 niños apropiados. Fuente: 


\section{Conclusiones}

La implementación de estudios de caso en la enseñanza de la biología y la salud, en especial para aquellas cuestiones de carácter complejo, es particularmente pertinente debido a la estructura propia de este formato. Precisamente la complejidad de algunos tópicos de estas áreas, en los que se involucran profundamente aspectos sociales, políticos e históricos, entre otros, reclaman para su abordaje que se contemplen dichos elementos tal como puede hacerse por medio de los casos. Miradas parciales de dichos tópicos solo conducen a abordajes limitados o deficientes que omiten la complejidad de los mismos y, por otra parte, se oponen a las prescripciones curriculares que demandan la adquisición, por parte de los estudiantes, de un pensamiento crítico habilitante para actuar eficientemente en la complejidad de las sociedades actuales. En este sentido, los estudios de caso, en función de las particularidades estructurales descriptas, se erigen como un dispositivo adecuado para su abordaje.

Por otra parte, las competencias de orden superior exigidas para su resolución favorecen la apropiación de una interpretación más potente y amplia de los conceptos involucrados en los casos y la puesta en marcha de procesos relacionados con la producción y comunicación de las ciencias.

El reconocimiento y la comprensión de la estrecha vinculación existente entre ciertos contenidos científicos escolares del área y las determinaciones sociales -así como las particularidades de su producción y evaluación- que pueden alcanzarse con la perspectiva propuesta, se constituye en una competencia de gran riqueza en una educación científica de calidad para todos.

\section{Referencias bibliográficas}

Alemany, I. (1998). Las bases teóricas de una propuesta didáctica para favorecer la comunicación en el aula. En J. Jorba, I. Gómez y A. Prat (eds.). Hablar y escribir para aprender (pp. 19-27). Barcelona: Síntesis.

Asimov, I. (1973). Introducción a la ciencia. Vol. II. Ciencias biológicas. Madrid: Hyspamérica.

Bernath, V. (2007). La identidad. Historias reales del ADN. Buenos Aires: Planeta.

Céline, L. (2009). Semmelweis. Barcelona: Marbot.

Claxton. G. (2001). Aprender. El reto del aprendizaje continuo. Barcelona: Paidós.

Dubos, R. (1953). Luis Pasteur. México: Gandesa.

Igartúa, J. (2011). Mejor convencer entreteniendo: comunicación para la salud y persuasión narrativa. Revista de Comunicación y Salud, 1(11), 69-83.

Lodge. D. (2002). El arte de la ficción. Barcelona: Península. Lozano, M. (2004). Ahí viene la plaga. Virus emergentes, epidemias y pandemias. Buenos Aires: Siglo XXI Editores.

Maglio, F. (2008). La dignidad del otro. Puentes entre la biología y la biografía. Buenos Aires: Zorzal.

Mc Ewan, H. y Egan, K. (2005). La narrativa en la enseñanza, el aprendizaje y la investigación. Buenos Aires: Amorrortu.

Schwab, J. (1978). Science, curriculum and liberal education. Chicago: University of Chicago Press.

Wasserman, S. (1994). El estudio de casos como método de enseñanza. Buenos Aires: Amorrortu. 